\title{
Desafíos y oportunidades para el turismo en el marco de la pandemia COVID-19
}

Vanesa Castello*

Con la aparición del COVID-19 a finales del año pasado en China se configuró un nuevo escenario de aprendizaje para la industria turística mundial. Considerando el contex to internacional cambiante, incierto y complejo, el presente artículo es una invitación a reflexionar sobre las dificultades que está atravesando la actividad turística, la cual, cabe remarcar, ha sido afectada por otras crisis en el sistema internacional en los últimos años, pero se ha mostrado siempre resiliente, logrando recuperarse rápidamente e incluso salir más fortalecida. Sin embargo, la escala e implicancias de la actual desaceleración son inéditas. Más aún, aunque la crisis terminara pronto, es poco probable que la actividad retome el curso tal cual venía desarrollándose.

Al mismo tiempo, debemos reconocer que como dice la famosa frase de Einstein, "es en la crisis donde nace la inventiva, los descubrimientos y las grandes estrategias". Diversas opiniones, se enfocan, por un lado, en estrategias de recuperación, ceñidas fundamentalmente en torno a aspectos y herramientas de índole económica para volver a la ¿normalidad?. Por otro lado, hay voces que se concentran en impulsar a partir de estas circunstancias un cambio cualitativo en la manera de hacer turismo.

Estamos de acuerdo que la presente crisis no tiene precedentes. Es una crisis sanitaria, social y económica por lo que es muy probable que este episodio modifique nuestras vidas tal cual las conocemos, tanto a nivel individual como colectivo. Por lo tanto, al no estar el sector turístico exento, presenciaremos un antes y un después en la actividad. De hecho, el mundo pareciera haberse detenido y el turismo no haber existido jamás.

En este sentido, es importante remarcar que la Organización Mundial del Turismo (OMT) considera que esta crisis tendrá un costo social tan importante que posiciona al turismo como el sector más afectado, haciendo que toda sus estimaciones y previsiones para este y los próximos años hayan quedado obsoletas por la realidad.

Es indudable que el impacto que los acontecimientos internacionales tienen en el turismo mundial está ligado a que dicha actividad involucra el movimiento, circulación y estancia de personas en lugares distintos al de su entorno habitual. Al mismo tiempo, es una gran generadora de ingresos para la mayoría de los países y ha sido potenciada por la globalización. Este complejo de múltiples interrelaciones, dependencias e interdependencias entre unidades geográficas, políticas, económicas y culturales, significa también la expansión, multiplicación y profundización de las relaciones sociales, de modo que las actividades cotidianas resultan cada vez más influidas por los hechos que ocurren en otras partes del globo. Es decir, acontecimientos que suceden en un lugar en principio claramente delimitado -en este caso China, donde se presentó el primer caso positivo de la

\footnotetext{
" Licenciada en Relaciones Internacionales, Universidad Nacional de Rosario (UNR, Argentina). Maestranda en Integración y Cooperación Internacional (CEI-CERIR-UNR). Profesora en las Cátedras de Geografía I de la Licenciatura en Turismo, y Elementos Generales de la Metodología en la Investigación Social de la Licenciatura en Relaciones Internacionales (UNR, Argentina). Correo electrónico: castellovanesa1@gmail.com
} 
enfermedad-, inexorablemente pueden tomar tal dimensión que repercuten en puntos del planeta muy alejados o remotos.

En este sentido, el turismo no sólo no escapa a esta realidad, sino que claramente es su viva representación. La mundialización de la economía, la revolución de las nuevas tecnologías comunicación, información, transporte-, los crecientes procesos de integración -sobre todo como grandes espacios que unifican y facilitan sus políticas en relación con la entrada, circulación y salida de turistas por sus territorios-, e iniciativas de cooperación entre regiones a fin de promover actividades en conjunto, revelan la interdependencia a la que el sector está sometido.

Hasta el presente, hemos sido testigos de los variados impactos que determinados acontecimientos internacionales han tenido en el turismo mundial. En algunos casos, devaluaciones de la moneda de un país receptor de turismo ha favorecido que un destino sea promocionado con mayor energía por los operadores turísticos -lo cual se denomina marketing turístico en relación a precios-. En otras oportunidades, conflictos bélicos han generado daños irreparables en la infraestructura y equipamiento de determinados destinos, y han provocado que hayan dejado de constituirse como las principales elecciones de los turistas por razones de seguridad. Asimismo, actos terroristas han ocasionado que determinado lugar vea disminuida la afluencia de turistas hacia su territorio, generando la explosión en términos de arribos de viajeros a otros destinos similares en sus características orográficas, naturales, culturales, entre otros. A modo de ejemplo, la devaluación del peso argentino a mediados del 2019 aceleró la promoción del país como destino accesible en términos cambiarios para el turismo extranjero, así como la guerra civil siria y la descomposición estatal en Irak han sido el contexto propicio para que grupos como ISIS destruyeran enclaves emblemáticos de alto valor histórico en ciudades como Alepo, Mosul o Palmira. En relación al impacto del terrorismo sobre determinados destinos turísticos, los atentados en Túnez y Egipto favorecieron que las Islas Canarias se constituyeran como la primera alternativa de los viajeros que hasta el momento optaban vacacionar en los países del Mediterráneo árabe.

Al mismo tiempo, el sector turístico contribuye a la expansión de otros sectores que forman parte de su cadena de valor, porque se encuentra ligado a un conjunto de actividades extendidas a lo largo del territorio de los Estados. Entre ellas encontramos al transporte, la hotelería, la gastronomía, la infraestructura, la construcción, la publicidad, el entretenimiento, paseos, comercios, y toda una serie de servicios asociados. Los ingresos y afluencia de los turistas contribuyen, así, a generar grandes aportes en la canasta de exportaciones de los países.

En este sentido, los indicadores que la OMT publicaba hasta inicios de este año claramente expresaban la importancia del turismo para la vida económica, social, política, cultural de nuestros países. Para reflejar esta última cuestión, con sólo mirar los informes del Barómetro del Turismo Mundial podemos graficar y dimensionar su magnitud: en 2019, la cifra de llegadas internacionales de turistas alrededor del mundo ascendió a 1.500 millones de personas, representando este dato un arribo de 4 millones de personas diariamente y un aumento del 4\% en relación a 2018; el sector continuaba contribuyendo con 1 de cada 10 empleos en el mundo; $7 \%$ de las exportaciones globales; y más del $10 \%$ del PBI mundial. Asimismo, las previsiones para finales de 2020 reflejaban expectativas de crecimiento de entre $3 \%$ y $4 \%$.

Si bien la crisis por el SARS de 2003 y la crisis económica mundial de 2009 son las referencias existentes, el fenómeno del COVID-19 ha modificado cualquier previsión posible ya que presenta características particulares, sobre todo en relación a las medidas que cada Estado ha tomado respecto a la protección de sus respectivas comunidades locales y en pos de evitar la propagación del contagio del virus. En este sentido, la OMT ha revisado sus perspectivas de 2020 para las llegadas de turistas internacionales a un crecimiento negativo de entre el $1 \%$ y el $3 \%$, lo que supone una pérdida estimada de entre 30 mil y 50 mil millones de dólares en ingresos procedentes del turismo internacional. En esta primera evaluación se espera que Asia y el Pacífico sea la región más afectada, con una caída prevista de las llegadas de entre el $9 \%$ y el 12\%. En la actualidad, las estimaciones para otras regiones del mundo son prematuras, habida cuenta de la rapidez y profundización con que evoluciona la situación. Los datos disponibles estiman que en Europa y América están en riesgo entre 8 y 10 millones de empleos respectivamente, producto de la crisis. 
Basado en los últimos desarrollos que han incluido medidas de cuarentena al interior de los países, prohibición de viajes internos e internacionales y cierres de fronteras en la mayor parte de Europa -que representa el 50\% del turismo internacional- y en muchos países de América, África y Medio Oriente, las evoluciones en Asia y el Pacífico y los patrones de las anteriores crisis, la OMT estima que las llegadas de turistas internacionales podrían disminuir entre un $20 \%$ y un $30 \%$ en 2020, cifra que parece bastante optimista según se están desarrollando los acontecimientos hasta el momento.

Esta caída prevista podría traducirse en un declive de los ingresos por turismo internacional -contabilizadas como exportaciones- de entre 300 mil y 450 mil millones de dólares, casi un tercio del billón y medio de dólares alcanzado en 2019. Teniendo en cuenta las tendencias pasadas de los mercados, esto significaría que, debido al COVID-19, se perdería el valor de entre cinco y siete años de crecimiento. Para poner estos datos en contexto, consideremos que en 2009, tras la crisis económica mundial las llegadas de turistas internacionales se redujeron un 4\%, mientras que en 2003 el brote de SARS llevó a un declive de tan solo el 0,4\%. Esta situación es más preocupante aún en los países receptores de turismo, si se considera que a escala mundial el $80 \%$ del sector está formado por pequeñas y medianas empresas, por lo cual el impacto social de la crisis irá mucho más allá del turismo como sector externo.

Es indudable la vorágine de los cambios. Hasta hace solo unos pocos meses, los debates principales giraban en torno al "sobreturismo", o el impacto negativo de la actividad en la calidad de vida de los ciudadanos y/o en la calidad de las experiencias de los visitantes por el llamado "exceso de carga" de un territorio, y a la "turismofobia" que en determinados destinos provocaba el rechazo en las comunidades locales por la excesiva concentración de viajeros en destinos populares a nivel global. Es decir, el turismo generaba conflictos y quejas por sus impactos en diversos temas como el sistema habitacional, alteraciones de los recorridos del transporte público para garantizar el acceso de turistas a atractivos en detrimento de los recorridos habituales para los residentes de esas ciudades, daños en el patrimonio cultural, social, así como graves impactos sobre el medioambiente. Cabe mencionar en este sentido los casos de Venecia y Machu Picchu que debieron restringir la entrada de turistas -ya sea por la instalación temporal de molinetes en el primer caso o el establecimiento de cupos diarios, en el segundo-, o el daño registrado en el patrimonio histórico de Dubrovnik a partir de la excesiva llegada de turistas para conocer los escenarios donde se filmó la serie Game of Thrones. No menos destacables, son los incidentes generados en Barcelona por los incendios a buses turísticos por parte de grupos locales "antiturismo".

Pero ahora, la preocupación por la saturación turística ha sido reemplazada por la preocupación alrededor de las restricciones en la circulación -las cuales no parecen vayan a modificarse en breve- y por los futuros cambios en el modo de viajar que amenazarían el devenir de las economías y sociedades de todo el mundo.

En función de lo hasta aquí mencionado, la pandemia del COVID-19 no podrá haber transitado los continentes sin producir algún tipo de repercusión sobre la actividad económica mundial, y en particular sobre la actividad turística. De todos modos, cualquier estimación debe tratarse con cautela y es probable que sea actualizada: toda evaluación del impacto de esta crisis incomparable en el sector turístico es rápidamente superada por la realidad cambiante. Esta crisis afectará a los países de distintas maneras y en distinto grado. La capacidad para responder y recuperarse también variará significativamente en función, por ejemplo, de las diferencias en infraestructuras, recursos humanos, capacidad económica o factores políticos.

Cualesquiera sean las consecuencias que esta pandemia tenga sobre el turismo en términos netamente económicos -sobre todo atendiendo a la importancia de la actividad en los PBI de los países-, lo que será inevitable es la forma en que los viajes se desarrollarán en el futuro en tanto destinos, frecuencias, traslados, alojamiento, medidas sanitarias de seguridad. Los cambios serán de tipo estructurales, y no coyunturales o de corto plazo.

A pesar de estas perspectivas -claramente irrefutables con sólo atender a cómo se están sucediendo los hechos- se abre una ventana para poner en discusión ahora más que nunca, la defensa y promoción del turismo sustentable. El decrecimiento del turismo, el cual no equivale a una desaceleración descontrolada ni al "antiturismo", supone la oportunidad para que la actividad se 
organice y se practique de una manera y a escala diferente, para evitar muchos de los impactos negativos asignados al sector. Somos testigos de la manera en que la menor circulación de las personas en los territorios ha generado la caída de los índices de polución ambiental, de contaminación de las aguas, y hasta el retorno de algunos animales salvajes a las calles de las ciudades. El objetivo es que cuando esta crisis aminore, una reducción voluntaria y planificada en el flujo y concentración de turistas tal cual los conocemos permita, sin dejar de promover la generación de empleo e ingresos para los países, maximizar los beneficios para las comunidades locales y el medioambiente.

A priori, parece que podrían presentarse algunos de los siguientes cambios en los modos de gestionar y realizar la oferta y la demanda turística. En relación a la gestión de la oferta turística por parte de Estados y/o agentes privados, las posibilidades pueden encontrarse en su diversificación para evitar la dependencia de una sola actividad o mercado; promover el mercado interno turístico y trabajar para que dichos viajes internos e intrarregionales sean más competitivos pero regulados; enfocarse en los cambios que se producirán en la demanda -entendida como las preferencias de los consumidores después de la crisis-; implementar programas de desarrollo turístico a regiones menos favorecidas y sobre poblaciones más amplias o diversificadas pero respetando sus culturas e identidades; ciudades o atracciones que restrinjan o limiten la cantidad de visitantes diaria.

Al considerar estos puntos es preciso tener en cuenta aquellas miradas que identifican como necesario el continuo crecimiento del turismo en la estructura básica de la economía capitalista. A partir de esta perspectiva, se ha recurrido cada vez más a la estimulación del crecimiento del turismo como un mecanismo para la recuperación económica en general, desatendiendo muchas veces los impactos negativos en los territorios y sus recursos. La pérdida de superficie de la Gran Barrera de Coral en Australia, el desarrollo de varios complejos turísticos sobre las playas de Phi Phi en Tailandia, o los daños sobre la estructura de sectores de la Muralla China son un reflejo de ello.

Desde el punto de vista de los turistas y los modos en que llevarán adelante sus viajes, algunos cambios que quizá presenciemos serán, entre otros: reservas en cruceros y hoteles más chicos, garantizando menores concentraciones de personas; servicios de comidas a la carta o con servicio buffet restringido para evitar la contaminación de alimentos; protocolos estrictos de limpieza para garantizar a los huéspedes la confianza en el servicio durante su estadía o traslado; aviones con menor cantidad de pasajeros, ya sea por una caída en la demanda como por la posibilidad que se implementen mayores espacios entre asientos ocupados; modificaciones en relación al vínculo que los viajeros establezcan con las agencias de viaje que tal vez vean un resurgir en su actividad atendiendo a que la demanda por falta de atención personalizada a la hora de solucionar problemas que se presentaron con cancelaciones, demoras, cobertura médica adecuada, son aspectos que generaron quejas en el uso de las .com cuando se desató la crisis.

Como reflexión final, y con los reparos que debemos atender por la volatilidad de los sucesos de los que estamos siendo testigos, la solución no sería prohibir o profundizar la restricción a la libertad de movimiento de las personas para realizar sus viajes de una manera irracional o aplicada sin planificación. Pero creemos que estas crisis tan profundas, que se extienden hacia todos los sectores de nuestra realidad, y que hasta llegan a amenazar nuestras vidas, nos habilitan a ser, como sugiere la frase que consideramos al principio de este artículo, creativos e ingeniosos.

Si bien por el momento cualquier tipo de análisis es coyuntural, es una necesidad ahora más que nunca apelar por un turismo ampliamente planificado, limpio, que contemple el medioambiente y la identidad, cultura y patrimonio local. Sin dejar de reconocer la importancia que el mismo tiene a nivel mundial en términos económicos, habrá que esperar a que esta crisis se supere y nos encontremos con la "nueva normalidad". De esta manera, seremos testigos de qué opción se elegirá: si pesará más la opinión de los impulsores del turismo entendido como un gigante económico al que hay que seguir promoviendo de manera intensiva y sin planificación para recuperarse de cualquier crisis, o si podremos enfrentar las consecuencias que el COVID-19 está dejando como una oportunidad para reconvertir y encarar esta actividad de modo tal que se recomponga, pero al mismo tiempo contribuya a hacerlo más sustentable. 